\title{
Incremental costs of hospital-acquired complications in Alberta, Canada
}

\author{
T Jackson ${ }^{1,2^{*}}$, A Fong $^{3}$, M Liu ${ }^{3}$, K Murray $^{4}$, L Walz ${ }^{3}, C_{\text {C Houston }}^{3}$, K Walker $^{3}$, S Dean $^{3}$ \\ From 27th Patient Classification Systems International (PCSI) Working Conference \\ Montreal, Canada. 19-22 October 2011
}

\section{Background}

Hospital-acquired diagnoses (HAD) not only lengthen inpatients' recovery times but also incur significant additional costs of care. The focus of previous research has been on 'highly preventable' indicator conditions and the cost of individual episodes, rather than on the entire spectrum of unintentional patient harm. As well, little attention has been paid to the frequency of HADs and resulting total costs.

\section{Objective}

The objective of this study was to estimate the incremental cost, aggregated system costs, and length-of-stay effects of hospital-acquired diagnoses in eight Alberta (Canada) hospitals.

\section{Methods}

Routinely coded diagnosis data, combined with a Present-on-Admission (POA) flag, were used to group 206,011 inpatient records into the 144 classes of the Classification of Hospital Acquired Diagnoses (CHADx). In Alberta's larger hospitals, costs are measured using sophisticated bottom-up, patient-level costing systems.

We employed a generalized linear model (GLM) with a gamma distribution using a log link relationship between the total cost of hospitalization and all 144 CHADx groups, after controlling for in-hospital death, one-day hospitalization, and the mean of uncomplicated cases in each CaseMix Group (CMG).

\section{Results}

Nearly a quarter of the sample (23.9\%) had at least one recorded hospital-acquired diagnosis. Across all cases,

\footnotetext{
* Correspondence: terri.jackson@ualberta.ca

'Division of Pulmonary Medicine, Faculty of Medicine and Dentistry,

University of Alberta, Edmonton, T6G 2C8, Canada

Full list of author information is available at the end of the article
}

any HAD was associated with increased costs of $\mathrm{C}$ $\$ 10,866$, more than double the mean cost of an uncomplicated admission, with a mean of 4.7 additional days of stay. CHADx representing the highest per-episode median incremental cost included multi-drug resistant Staph aureus (CHADx 4.3, C $\$ 11,357$ ), falls with fractured neck of femur (CHADx 3.1, C\$6,679), and pressure ulcers (CHADx 8.1, C $\$ 6,512)$. Twenty-two CHADx added $>2$ days to the median for a similar but uncomplicated stay.

Taking the volume of cases into account, and using an approximation of the mean incremental cost to capture all system costs, urinary tract infection (CHADx 9.2) was the most costly, adding $C \$ 19.3$ million to system costs. CHADx responsible for the greatest extension of LOS (length of stay) across the system were similar to those adding the greatest costs, with the notable additions of Clostridium difficile infection (CHADx 7.3, $+8,813$ days) and septicaemia (CHADx 4.1, $+6,284$ ).

High-level grouping of CHADx showed hospitalacquired infections to be the mostly costly type of complication, adding $\mathrm{C} \$ 49.6$ million, although this finding is sensitive to the way in which HAD conditions are grouped.

\section{Discussion}

Few hospital-acquired diagnoses are preventable in every case, but most have been shown to be amenable to a reduction in their rates. POA flags on routine diagnosis data considerably improve the ability to identify compromised patient care, although such data will remain controversial without further efforts to improve medical record documentation. Adding financial and length-ofstay dimensions to discussions about hospital quality improvement may strengthen efforts to reduce harm to patients, as will timely access to local data. 


\section{Acknowledgements}

The authors wish to thank Alberta Health Services for access to de-identified patient-level data. However, we note that this paper is not endorsed by Alberta Health Services, nor does it represent official AHS policy.

This study was granted ethical approval by the Human Research Ethics Board of the University of Alberta.

\section{Author details}

'Division of Pulmonary Medicine, Faculty of Medicine and Dentistry, University of Alberta, Edmonton, T6G 2C8, Canada. ${ }^{2}$ Health Policy and Management, School of Public Health, University of Alberta, Edmonton, T6G 2C8, Canada. ${ }^{3}$ Data Integration Measurement and Reporting, Strategy and Performance, Alberta Health Services, Calgary, Canada. ${ }^{4}$ Provincial Operations, Standards and Strategies, Health Information, Alberta Health Services,

Calgary, Canada.

Published: 19 October 2011

doi:10.1186/1472-6963-11-S1-A15

Cite this article as: Jackson et al:: Incremental costs of hospital-acquired complications in Alberta, Canada. BMC Health Services Research 201111 (Suppl 1):A15.

\section{Submit your next manuscript to BioMed Central} and take full advantage of:

- Convenient online submission

- Thorough peer review

- No space constraints or color figure charges

- Immediate publication on acceptance

- Inclusion in PubMed, CAS, Scopus and Google Scholar

- Research which is freely available for redistribution

Submit your manuscript at www.biomedcentral.com/submit 